\title{
Re-Establishment and Maintenance of Geodetic Networks in Parts of Oyo State Using Modern Techniques
} Ikharo I. Blessing ${ }^{1}$, Matthew N. Ono², Olaniyi Saheed S. ${ }^{3}$

Nnamdi Azikiwe University, Awka Anambra State, Nigeria

\begin{abstract}
Oyo state like most of the other states in the Nigeria has an old and conventional Geodetic Network. This network was established and computed using the conventional method of position determination and the science of navigation in the 1930- 1950's which is based on the 30th arc-meridian of the Clarke 1880 modified ellipsoid with its origin at L40 Minna datum. This does not satisfy the overgrowing mapping requirements of the state and as well as other Geo-related information requirements. The required data were acquired with GNSS receivers set up on each of the existing points in static mode. The reference network that was reestablished consists of eight (8) primary points, covering an area of approximately $12 \mathrm{~km}^{2}$ with an average separation of about $7 \mathrm{Km}$. The new network monuments are made of reinforced concrete, solidly cemented in the ground with metal caps (brass markers), and coordinated using the static carrier phase differential GPS measurement. Several observation sessions were conducted and processed to compute 3D coordinates for the network. Post processed data were rigorously adjusted using Least Squares and must meet the distance accuracy specifications for a first order network (1:100,000). Final coordinates are based on WGS84 frame/ ITRF 2008 datum and are within a mean accuracy of \pm 0 . $05 \mathrm{~m}$. Finally, the plots of the re-established control points were presented and thus re-established a reliable first order geodetic reference network within Oyo state. Based on the findings the study recommends all geodetic networks in Nigeria should be re- established.
\end{abstract}

Keywords: Geodetic, GPS, GNSS, Least Squares Adjustment, Oyo, Mapping

\section{INTRODUCTION}

The emergence of Global Positioning System (GPS) has transformed the conventional method of position determination and the science of navigation. GPS is a satellite positioning system based on one-way ranging in which the measurement of travel time of a signal from transmitter to receiver is achieved by the application of separate clocks; the transmitter (GPS satellites in space) and the receiver clock (GPS receivers on the earth's surface) [1].

The Differential Global Positioning System (DGPS) involves position determination of a rover station with reference to a base station, which observes the same positional satellites in space simultaneously with pseudo-range correction being effected. This could be post-processed or real-time by radio transmission. The purpose of Differential correction in DGPS positioning is to provide a higher accuracy in GPS position determination which is not achievable in Precise Point Positioning (PPP).

The Global Navigation Satellite System (GNSS) has dramatically changed the way that surveyors and other professional engineers measure positional coordinates. These experts can now measure spatial distances - baselines and estimate 3D coordinates of a 
new point (rover) relative to a reference located from a few to many tens of kilometres away[2].

This range/baseline defined by the distance between the rover and the base station is a position vector whose origin is at the base station. Thus, the position vector of the rover station defines the DGNSS baseline (range vector). In DGNSS positioning, the increase in the baseline affects the accuracy of the determined position and this accuracy is also a function of the satellite geometry. It is also worthwhile to note that satellite geometry has an amplifying effect on other GNSS sources of error [3].

Recent development in GNSS has led to a paradigm shift from passive network of geodetic controls to active Continuously Operating Reference Station (CORS). The active stations are continuously developed into a network system capable of reducing the number of stations over a coverage area by extending baseline length and at the same time improving the accuracy of processing the baselines between the reference stations and the rovers. This could be achieved either from a networked GNSS station where all stations are linked to a central control station for data correction and modelling or the most advanced technique nowadays based on the Virtual Reference Station (VRS) network concept (Retscher, 2002).

Based on the evidence available from the historical development of the primary control network [4] and the analysis of the network after 1997 adjustment sited in [5], it is evident that the Nigerian Geodetic Horizontal control network is distorted by significant amount both in scale and orientation caused by human activities. Accuracy of the geodetic network generally decreases with time, resulting from the errors inherent in observation over time which is the usual scenario in Nigeria traditional methods because of these natural and man- made actions, some of the geodetic control points are no more in-situ, destroyed and in most cases non- existence. This situation makes mapping and surveying difficult and some instances not possible.

Therefore, this study is very necessary because the geodetic networks that were established using Triangulation (traditional methods) will be reestablished and updated using modern method (GNSS). It aims at creating a reliable network, that will be accessible by everyone without any charges. It will serve as a pilot project for the future densification of the National Geodetic Network. It is important to maintain these networks using modern technologies to correct these anomalies in order to re-establish relatively standard metric values for the state. This study scope as shown in figure 1, covers the re-establishment and maintenance of the geodetic control points in the ancient city of Oyo located within Latitude 7o $00^{\prime} 00 \mathrm{~N}$ and 9o 00 '00 N, and Longitude 3 $00^{\prime} 00 \mathrm{E}$ and 4o 30'00 E. GNSS receivers were used to accurately determine their positions. The new positions were determined based on WGS 84/ ITRF 2008 datum. The observed baselines were subjected to Least Squares Adjustment in order to obtain new coordinates for the points. Eight (8) geodetic points were re-established and maintained.

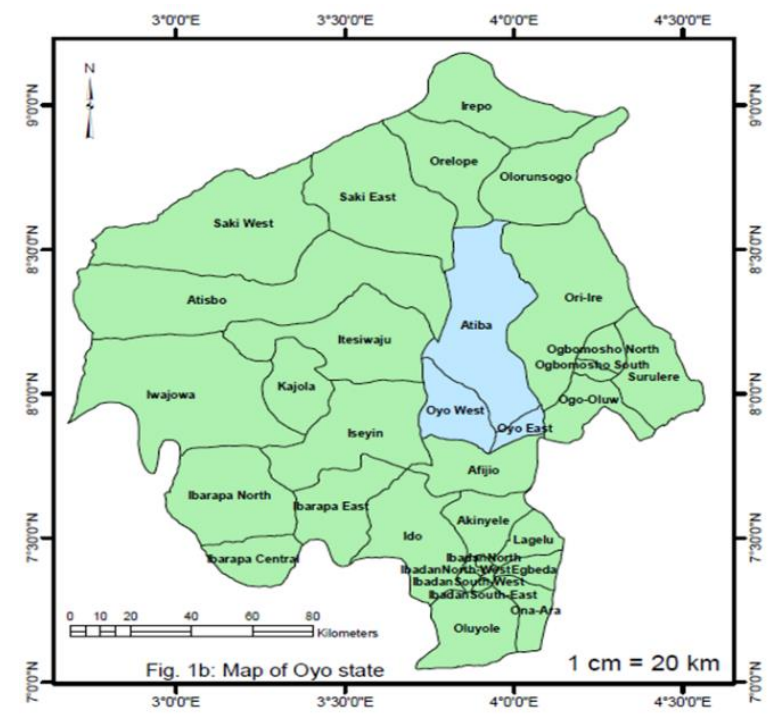


Figure 1 : Map of Oyo State Showing Oyo East, Oyo West, and Atiba Local Government Area of Oyo state Source: [6]

\section{METHODS AND MATERIAL}

The following activities and materials were used for the execution of this research. These activities are Project Planning (Office Planning), Field Reconnaissance, Monumentation, GPS field Observation, data processing, Least Squares adjustment and Analysis of Result

The procedures are shown in the methodology flowchart in Figure 2;

\section{Materials used}

The materials used for the projects which consists of hardware and software are as follows;

i. Four (4) units of Trimble R4 GNSS Receivers and its accessories

ii. Garmin 76 CSX Handheld GPS receiver

iii. Dell Inspiron (1545) computer system

iv. Digital Camera

v. Inkjet Printer

vi. Linen tape

vii. Field book

viii. Trimble Business Centre

ix. Geographic Calculator

x. ADJUST for GNSS baseline Adjustment

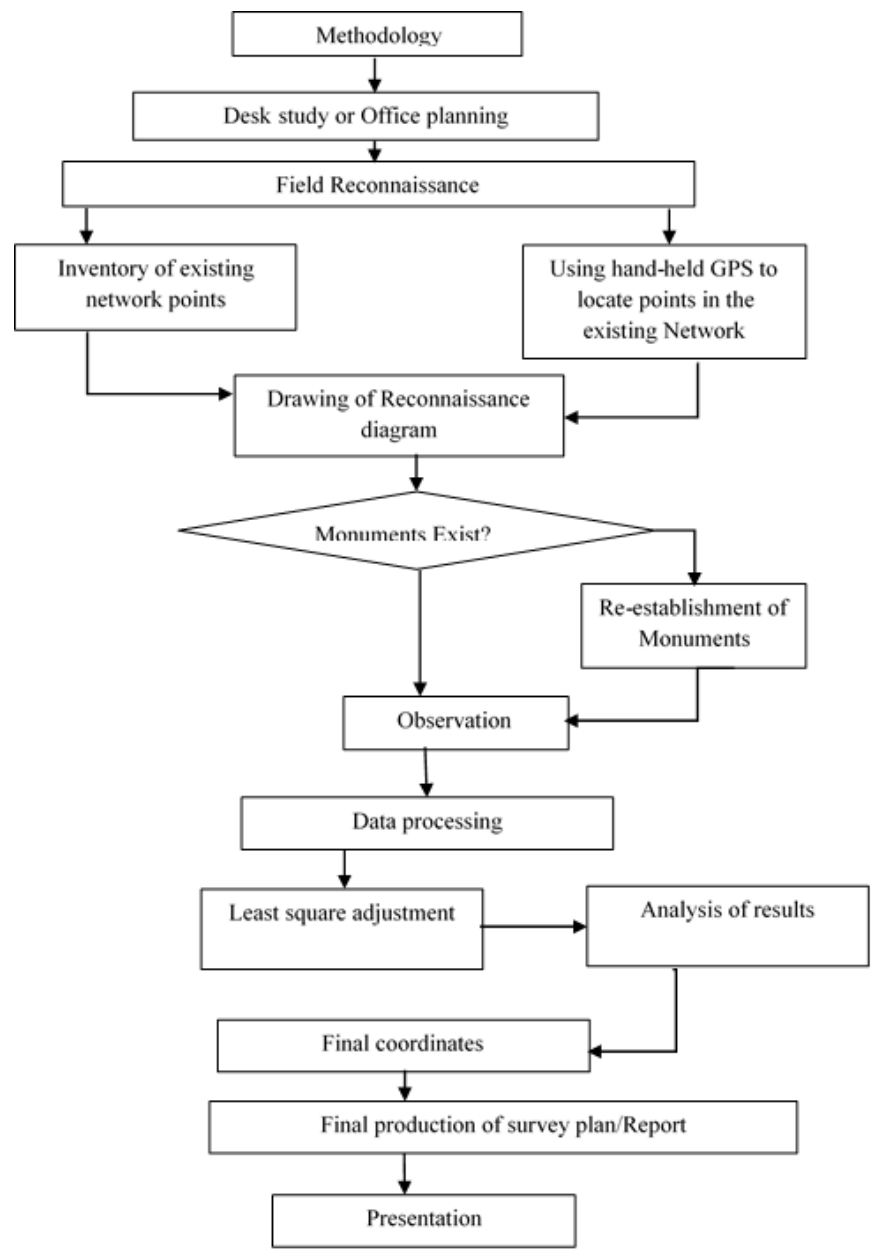

Figure 2: Methodology Flow chart

\section{Project Planning}

Planning for this project was done in two phases; phase one involved activities covering field reconnaissance. Phase two included activities ranging from searching for the official record of the geodetic network, field measurements to post-processing. Phase one focused on planning the sequence of visitation to existing points considering the available resources.

\section{Office Planning}

Little is known about the existing geodetic network in Oyo. The long years of inaccessibility and neglect paralyzed some of the geodetic infrastructure. The 
SIWES Department of the Federal School of Surveying, Oyo was only able to provide some information on the first order stations within Oyo, which are part of the existing network. See table 1 below for the information of the existing geodetic network.

Table 1: Coordinates of Geodetic Control Points in Oyo

\begin{tabular}{|c|c|c|c|c|c|c|c|}
\hline \multirow{2}{*}{$\begin{array}{l}\text { Stn. } \\
\text { ID }\end{array}$} & \multicolumn{2}{|c|}{ UTM Zone 31 Coordinates } & \multicolumn{2}{|c|}{ Geographic Coordinates } & \multirow{2}{*}{$\begin{array}{l}\text { Elev } \\
(\mathrm{m})\end{array}$} & \multirow[t]{2}{*}{ Stn. Location } & \multirow[t]{2}{*}{ Remark } \\
\hline & $\begin{array}{l}\text { Eastings } \\
\text { (m) }\end{array}$ & $\begin{array}{l}\text { Nothings } \\
\text { (m) }\end{array}$ & Latitude & Longitude & & & \\
\hline $\begin{array}{l}\mathrm{XSN} \\
07\end{array}$ & 604753.215 & 866889.923 & $7^{0} 50^{\prime} 31.5^{\prime \prime} \mathrm{N}$ & $3^{0} 57^{\prime} 00.7^{\prime \prime} \mathrm{E}$ & 313 & FSS & Accessible \\
\hline Y1 & 601525.001 & 871356.966 & $7^{0} 52^{\prime} 57.2^{\prime \prime} \mathrm{N}$ & $3^{0} 55^{\prime} 15.4^{\prime \prime} \mathrm{E}$ & 327 & KOSO HILL & $\begin{array}{l}\text { Difficult to } \\
\text { access }\end{array}$ \\
\hline $\mathrm{Y} 2$ & 597331.112 & 870584.130 & $7^{0} 52^{\prime} 32.4^{\prime \prime} \mathrm{N}$ & $3^{0} 52^{\prime} 58.5^{\prime \prime} \mathrm{E}$ & 295 & ERELU HILL & Accessible \\
\hline $\mathrm{Y3}$ & 600101.925 & 873672.199 & $7^{0} 54^{\prime} 12.0^{\prime \prime} \mathrm{N}$ & $3^{0} 54^{\prime} .00^{\prime \prime} \mathrm{E}$ & 304.188 & $\begin{array}{l}\text { BOSERO } \\
\text { HILL }\end{array}$ & $\begin{array}{l}\text { Difficult to } \\
\text { access }\end{array}$ \\
\hline $\mathrm{Y} 4$ & 598723.437 & 872018.169 & $7^{0} 53^{\prime} 19.0^{\prime \prime} \mathrm{N}$ & $3^{0} 53^{\prime} 44.0^{\prime \prime} \mathrm{E}$ & 265 & $\begin{array}{l}\text { ATAMBATA } \\
\text { HILL }\end{array}$ & Accessible \\
\hline Y5 & 600566.219 & 877673.186 & $7^{0} 55^{\prime} 26.7^{\prime \prime} \mathrm{N}$ & $3^{0} 58^{\prime} 50.6^{\prime \prime E}$ & 329.224 & $\begin{array}{l}\text { IKOLOBA } \\
\text { HILL }\end{array}$ & $\begin{array}{l}\text { Difficult to } \\
\text { access }\end{array}$ \\
\hline Y11 & 598265.491 & 874125.858 & $7^{0} 54^{\prime} 27.6^{\prime \prime} \mathrm{N}$ & $3^{0} 53^{\prime 2} 29.3^{\prime \prime} \mathrm{E}$ & 359 & $\begin{array}{l}\text { AGIDAN } \\
\text { HILL }\end{array}$ & $\begin{array}{l}\text { Difficult to } \\
\text { access }\end{array}$ \\
\hline $\begin{array}{l}\mathrm{OWI} \\
\mathrm{NNI}\end{array}$ & 606848.199 & 872047.886 & $7^{0} 53^{\prime} 19.3^{\prime \prime} \mathrm{N}$ & $3^{0} 58^{\prime} 9.4^{\prime \prime} \mathrm{E}$ & 350 & $\begin{array}{l}\text { OWINNI } \\
\text { HILL }\end{array}$ & Accessible \\
\hline
\end{tabular}

\section{Field Reconnaissance}

Reconnaissance for this project included two major activities; inventory of existing network points, and identification of sites for the new network stations. However, field trips to those points showed that the points are there but very difficult to access. Most of the points in the old network were established using conventional triangulation methods. The points are therefore situated at extreme heights of the hills. Their existing coordinates were entered into Garmin 76CSX handheld GPS for easy navigation and location of the existing geodetic points. The coordinates values did not match with the ground position of the geodetic points.
For the purpose of collecting accurate data, consideration was taken on periods of the day when there will be at least four satellites in view and a suitable corresponding Positional Dilution of Precision (PDOP). Session planning for this project considered the following steps,

(i) A plot was made, displaying all the control stations that were to be occupied and the planned vectors between them.

(ii) Lengths of sessions were determined based on the results obtained by the following formula, which sets 30 minutes as the minimum for a static GPS survey: 
(iii) $L=\frac{\text { max baseline }(m)}{125} \times \frac{4}{\text { No of satellites in view }}$

(1)

$\mathrm{L}$ is the length of session in minutes. However, for the purposes of obtaining higher accuracies, all sessions were observed for a minimum of one (1) hour. This time exceeded all session lengths computed from the above formula.

(i) Logistics were properly planned, such as time needed for moves between stations, matching the right operators for the more difficult assignments, and the efficient use of "Leapfrogging" techniques. Finally,

(ii) Field session forms, station location maps, descriptions and work assignments were prepared for completion during the sessions.

The points under study are within the Nigerian primary triangulation networks which were established on the peak of hills. The locations of the points are as follows; XSN07 - located inside Federal School of Surveying, Oyo, Y5 - located on Ikolaba hill, L11 - located on Agidan hill, Y3 - Bosero hill, Y5 - located on Owinni hill, Y2 - located on Erelu hill and Y1 - located on Koso hill.

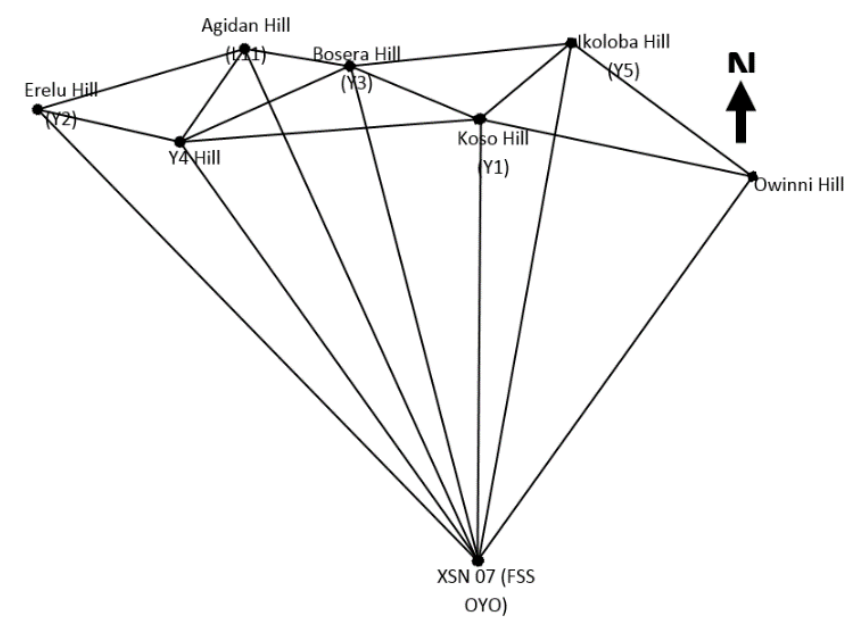

Figure 3: Reconnaissance Diagram (not to scale)

\section{Control Check and Analysis of Fixed Baseline Measurements}

Job specification often requires that Baseline observations be taken between fixed control stations as shown in table 2 . The benefits of making these observation is to verify the accuracy of both the observational process and the control been held fixed. Obviously, smaller discrepancies between observed and known baseline length mean better precision. If the discrepancies are too large to be tolerated, the condition causing them must be investigated.

Control Points - Coordinates (UTM, Minna Zone 31)

XSN $07=604755.785 \mathrm{mE}, 866879.142 \mathrm{mN}, 309.972 \mathrm{mH}$

FSS $\quad 1 / \quad 24 \quad=601944.758 \mathrm{mE}, \quad 858841.654 \mathrm{mN}$, $271.135 \mathrm{mH}$

Table 2 : Showing Baseline Vectors from Observation

\begin{tabular}{|l|l|l|l|l|}
\hline From & To & $\Delta \mathrm{X}(\mathrm{m})$ & $\Delta \mathrm{Y}(\mathrm{m})$ & $\Delta \mathrm{Z}(\mathrm{m})$ \\
\hline $\begin{array}{l}\mathrm{XSN} \\
07\end{array}$ & FSS & 1244.386 & -2750.822 & -7964.617 \\
& & & & \\
\hline
\end{tabular}

The following steps were adopted for the analysis; The coordinates of the control points were converted from their geodetic values into the Earth-Centered $\mathrm{Xe}, \mathrm{Ye}, \mathrm{Ze}$ geocentric System. The equations for making these conversions;

$\mathrm{X}=(\mathrm{N}+\mathrm{H}) \cos \varphi \cos \lambda$

$\mathrm{Y}=(\mathrm{N}+\mathrm{h}) \cos \varphi \sin \lambda$

$\mathrm{Z}=\left[\mathrm{N}\left(1-e^{2}\right)+\mathrm{h}\right] \sin \varphi$

In the equation above, $\mathrm{h}$ is the geodetic height of the point, $\varphi$ is the geodetic Latitude, $\lambda$ is the geodetic Longitude, e is the eccentricity for the ellipsoid, which is computed as 


$$
\begin{gathered}
e^{2}=2 \mathrm{f}-f^{2} \quad \text { or } \\
e^{2}=\frac{a^{2}-b^{2}}{a^{2}} \\
\mathrm{~N}=\frac{a}{\sqrt{1-e^{2} \sin ^{2} \phi}} \\
\lambda=\tan ^{-1} \frac{Y}{X} \\
\mathrm{D}=\sqrt{X^{2}+Y^{2}} \\
\phi_{0}=\tan ^{-1} \frac{Z}{D\left(1-e^{2}\right)} \\
N_{0}=\frac{a}{\sqrt{1-e^{2} \sin ^{2} \phi_{0}}} \\
\phi_{0}=\tan ^{-1} \frac{Z+e^{2} N_{0} \sin \phi_{0}}{D} \\
\mathrm{~h}=\frac{D}{\operatorname{Cos} \phi_{0}}-N_{0}
\end{gathered}
$$

\begin{tabular}{|c|c|c|c|}
\hline POINTS & $\varphi$ & $\lambda$ & $\mathrm{H}$ \\
\hline XSN 07 & $\begin{array}{lc}7^{\circ} \quad 50 \\
28.91567^{\prime \prime}\end{array}$ & $\begin{array}{l}3^{\circ} 57^{\prime} \\
00.71296^{\prime \prime}\end{array}$ & 335.806 \\
\hline FSS1/ 24 & $\begin{array}{l}7^{\circ} \quad 46^{\prime} \\
07.41915^{\prime \prime}\end{array}$ & $\begin{array}{l}3^{\circ} \quad 55^{\prime} \\
28.35434^{\prime \prime}\end{array}$ & 297.001 \\
\hline
\end{tabular}

The geodetic coordinates value of the two (2) control points used are shown in Table 3 below;

Table 3 : The geodetic coordinates values

The geocentric equivalent of the geodetic coordinates shown in Table 3 above were obtained using GEOCAL Software (coordinate Transformation) and the result is shown in Table 4: below;

Table 4 : The Geocentric Coordinates

\begin{tabular}{|l|l|l|l|}
\hline $\begin{array}{c}\text { POINT } \\
\text { S }\end{array}$ & \multicolumn{1}{c|}{ X } & \multicolumn{1}{c|}{ Y } & \multicolumn{1}{c|}{ Z } \\
\hline XSN 07 & $\begin{array}{l}6304212.689 \\
0\end{array}$ & $\begin{array}{l}435327.361 \\
4\end{array}$ & 864448.858 \\
& 0 & 4 \\
\hline $\begin{array}{l}\text { FSS 1/ } \\
24\end{array}$ & 6305457.077 & 432576.538 & 856484.240 \\
\hline
\end{tabular}

Table 5 : The Comparison of Measured and Fixed Baseline Components

\begin{tabular}{|l|l|l|l|l|}
\hline $\begin{array}{c}\text { Compone } \\
\mathrm{nt}\end{array}$ & $\begin{array}{c}\text { Measured( } \\
\mathrm{m})\end{array}$ & Fixed (m) & $\begin{array}{c}\text { Differen } \\
\text { ce }(\mathrm{m})\end{array}$ & $\begin{array}{c}\mathrm{pp} \\
\mathrm{m}\end{array}$ \\
\hline$\Delta \mathrm{X}$ & +1244.386 & $\begin{array}{l}+1244.38 \\
89\end{array}$ & -0.0029 & - \\
& & 89 & & 0.3 \\
$4 \mathrm{Y}$ & -2750.822 & - & -0.0011 & - \\
\hline & & 2750.823 & & 0.1 \\
& & 1 & & 3 \\
\hline $\mathrm{Z}$ & -7964.617 & - & -0.0009 & - \\
& & 7964.617 & & 0.1 \\
& & 9 & & 1 \\
\hline
\end{tabular}

The fixed baseline length is obtained by the square root of sum of the squares of $\Delta \mathrm{X}, \Delta \mathrm{Y}$ and $\Delta \mathrm{Z}$ values.

Baseline Length $\left.=\sqrt{\left(\Delta X^{2}+\Delta Y^{2}\right.}+\Delta Z^{2}\right)$

$\sqrt{ }(1244.386)^{2} \quad(-2750.822)^{2}+(-7964.617)^{2}=$ 8517.668

The ppm values were obtained by dividing the differences by their corresponding total baseline and multiplying by 1000 000. The ppm values are acceptable for the required order of accuracy for the survey according to specification for the establishment of Geodetic Controls in Nigeria.

\section{GPS Observation}

Field measurements were carried out over a period of four (4) days; August 15th to August 18th, 2018. The long distances between the points, the bad roads, and having only one vehicle did not permit us to have more than one session per day. 


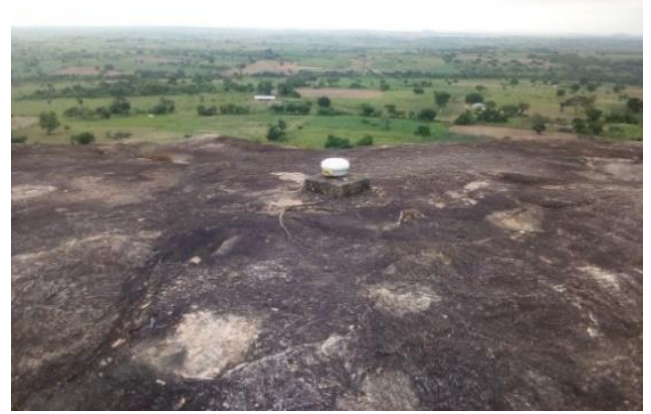

Figure 4 a

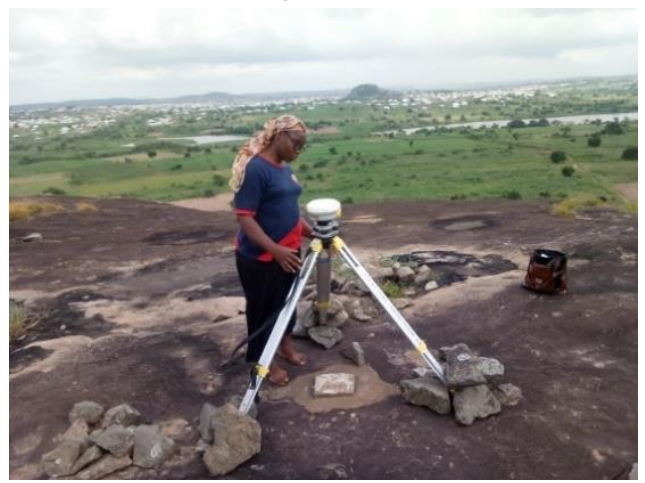

Figure $4 \mathrm{~b}$

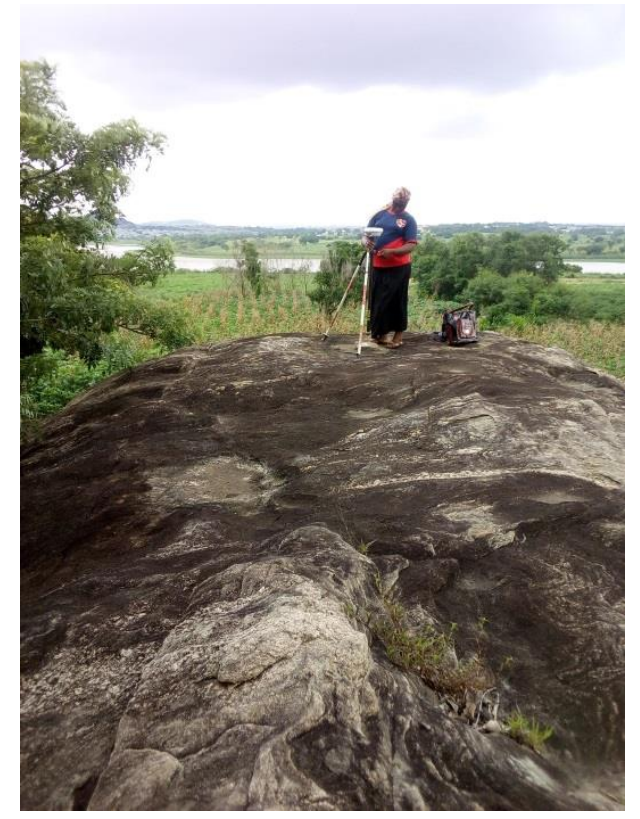

Figure $4 \mathrm{c}$

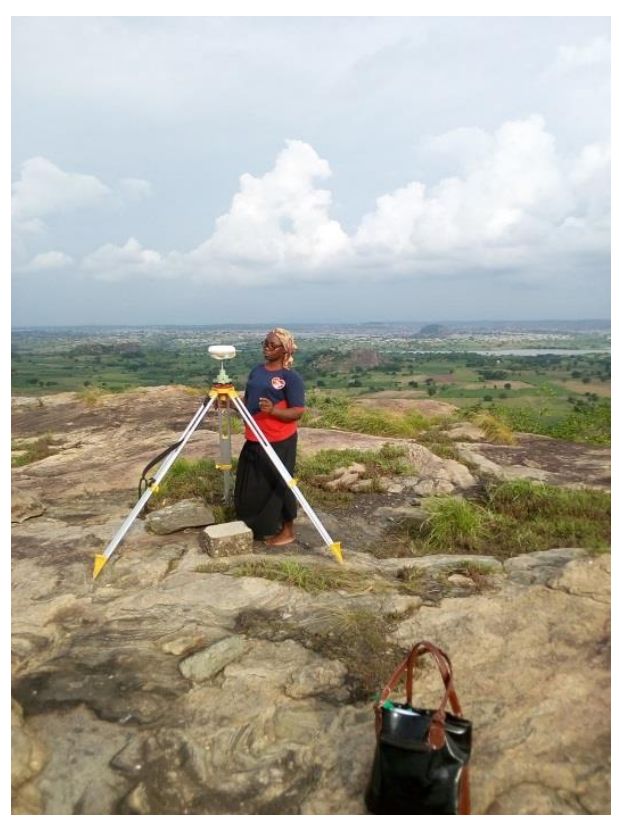

Figure $4 \mathrm{~d}$

Figures 4 a,b,c and d: Showing setting up of four (4) units of Trimble R4 GNSS Receivers for static carrier phase differential measurements. The static carrier phase differential measurement using GNSS receivers was used for the observations of each baseline in the network. Two (2) hour sessions were observed at each point, and four receivers were used simultaneously (one base and three rovers) during each observation. This method forms a triangulated network of baselines and gives the network a good stability. It also simplifies the calculations and makes error detection easier in the formed baseline loops. The GPS observation sessions involving rover stations were carried out using suitable field procedures given in [7] and [8]. Antenna heights for both the base and rover stations were carefully measured and recorded before and after each session.

Field measurements were also done around each point, detailing permanent nearby structures and road intersections, to give a graphic description of the points for the purpose of easily locating them. 


\section{Data Processing}

\section{RESULTS AND DISCUSSION}

Data processing for this project underwent two stages: preliminary and final processing. Field data was initially downloaded and processed using Trimble Business Centre. The baselines were computed by Trimble Business Centre (TBC). This preliminary processing was carried out to judge if the data collected was of adequate quality for this project.

At this stage, the baseline vectors and covariance element for each observed baselines were extracted from the processed results. The results are shown in the table below

Table 6 : Baselines Vector Covariance Matrix Element

\begin{tabular}{|c|c|c|c|c|c|c|c|c|c|c|}
\hline From & To & $d X$ & dY & $d z$ & \multicolumn{6}{|c|}{ Covariance Matrix Elements } \\
\hline XSN07 & OWINNI & -817.429 & 2054.853 & 5111.216 & $2.60 \mathrm{E}-04$ & $2.80 \mathrm{E}-05$ & $5.70 \mathrm{E}-05$ & $9.50 \mathrm{E}-06$ & $6.50 \mathrm{E}-06$ & $1.60 \mathrm{E}-05$ \\
\hline XSN07 & $\mathrm{Y5}$ & -1661.05 & 3258.909 & 10815.91 & $2.90 \mathrm{E}-03$ & $2.40 \mathrm{E}-05$ & $4.10 \mathrm{E}-05$ & $6.30 \mathrm{E}-06$ & $3.30 \mathrm{E}-06$ & $9.10 \mathrm{E}-06$ \\
\hline XSN07 & Y1 & -380.512 & -3255.34 & 4436.223 & $9.00 \mathrm{E}-04$ & $4.90 \mathrm{E}-05$ & $1.00 \mathrm{E}-04$ & $7.20 \mathrm{E}-06$ & $4.80 \mathrm{E}-06$ & $2.20 \mathrm{E}-05$ \\
\hline XSNO7 & Y3 & -617.26 & -4693.13 & 6730.45 & 7.40E-05 & $3.00 \mathrm{E}-06$ & $1.10 \mathrm{E}-05$ & $4.60 \mathrm{E}-06$ & $1.10 \mathrm{E}-06$ & 4.60E-06 \\
\hline XSN07 & $\mathrm{Y} 4$ & -334.717 & -6059.16 & 5085 & $2.10 \mathrm{E}-04$ & $1.50 \mathrm{E}-05$ & $3.70 \mathrm{E}-05$ & 4.00E-06 & $\mathrm{E}-06$ & $9.10 \mathrm{E}-06$ \\
\hline XSN07 & $\mathrm{Y} 2$ & -19.88 & -7436.59 & 3675.543 & $3.00 \mathrm{E}-04$ & $1.70 \mathrm{E}-05$ & $3.90 \mathrm{E}-05$ & $4.50 \mathrm{E}-06$ & $3.10 \mathrm{E}-06$ & $7.70 \mathrm{E}-06$ \\
\hline XSN07 & L11 & -505.818 & -6525.29 & 7190.83 & 4.70E-04 & $-7.20 \mathrm{E}-06$ & $9.20 \mathrm{E}-05$ & 7.10E-06 & $3.00 \mathrm{E}-06$ & $2.30 \mathrm{E}-05$ \\
\hline Y5 & OWINNI & 843.554 & -1204.09 & -5704.71 & E-04 & $\mathrm{E}-04$ & $\mathrm{E}-05$ & $\mathrm{E}-04$ & $\mathrm{E}-06$ & $\mathrm{E}-05$ \\
\hline Y5 & Y3 & 1043.806 & -7952.03 & -4085.46 & 1.00E-04 & 1.40E-06 & 1.70E-05 & 2.60E-06 & $-4.40 \mathrm{E}-08$ & $4.80 \mathrm{E}-06$ \\
\hline Y4 & $\mathrm{Y3}$ & -282.513 & 1366.036 & 1640.638 & $2.00 \mathrm{E}-04$ & $4.20 \mathrm{E}-05$ & 4.80E-05 & $1.80 \mathrm{E}-05$ & $1.00 \mathrm{E}-05$ & $1.70 \mathrm{E}-05$ \\
\hline Y4 & Y2 & 314.845 & -1377.42 & -1414.29 & $1.50 \mathrm{E}-05$ & $1.70 \mathrm{E}-06$ & 1.90E-06 & 2.00E-06 & $7.90 \mathrm{E}-07$ & $1.80 \mathrm{E}-06$ \\
\hline Y5 & Y1 & 1280.279 & -6514.26 & -6379.72 & $1.80 \mathrm{E}-04$ & $1.20 \mathrm{E}-05$ & 2.60E-05 & 4.70E-06 & $1.90 \mathrm{E}-06$ & 7.50E-06 \\
\hline Y5 & L11 & 1155.304 & -9784.2 & -3625.05 & $3.60 \mathrm{E}-04$ & $-1.40 \mathrm{E}-06$ & $6.50 \mathrm{E}-05$ & $6.70 \mathrm{E}-06$ & $-1.60 \mathrm{E}-06$ & $1.70 \mathrm{E}-05$ \\
\hline $\mathrm{Y4}$ & L11 & -170.929 & -466.126 & 2101.051 & 7.00E-05 & 7.60E-06 & 1.00E-05 & $2.10 \mathrm{E}-06$ & $1.20 \mathrm{E}-06$ & $2.80 \mathrm{E}-06$ \\
\hline Y3 & L11 & 111.602 & -1832.15 & 460.415 & 4.40E-06 & $1.20 \mathrm{E}-07$ & $8.80 \mathrm{E}-07$ & 1.00E-06 & $-2.70 \mathrm{E}-08$ & $1.20 \mathrm{E}-06$ \\
\hline Y4 & Y1 & -45.833 & 2803.813 & -653.599 & $7.40 \mathrm{E}-05$ & $4.80 \mathrm{E}-06$ & $1.80 \mathrm{E}-05$ & $6.30 \mathrm{E}-06$ & $1.80 \mathrm{E}-06$ & $1.80 \mathrm{E}-05$ \\
\hline Y3 & $\mathrm{Y} 1$ & 236.709 & 1437.783 & -2294.23 & $5.80 \mathrm{E}-05$ & $3.80 \mathrm{E}-06$ & $1.20 \mathrm{E}-05$ & $6.90 \mathrm{E}-06$ & $1.40 \mathrm{E}-06$ & 1.10E-05 \\
\hline
\end{tabular}

\section{Network Pre-Adjustment Data Analysis}

Prior to adjusting GPS networks, a series of procedures should be followed to analyze the data for internal consistency and to eliminate possible blunders [9]. No control points are needed for these analyses. Depending on the actual observations taken and the network geometry, these procedures may consist of analyzing (1) differences between fixed and observed baseline components, (2) differences between repeated observations of the same baseline components, and (3) loop closures. For the purpose of this project, a loop closure analysis was employed.

\section{Analysis of Loop Closures}

The GPS network in figure (5) consists of many interconnected closed loops. For example, a closed loop is formed by points $A B G A$. Similarly, $A D F A, A E F A$, and so on, are other closed loops. For each closed loop, the algebraic sum of the $X$ components should equal zero. The 


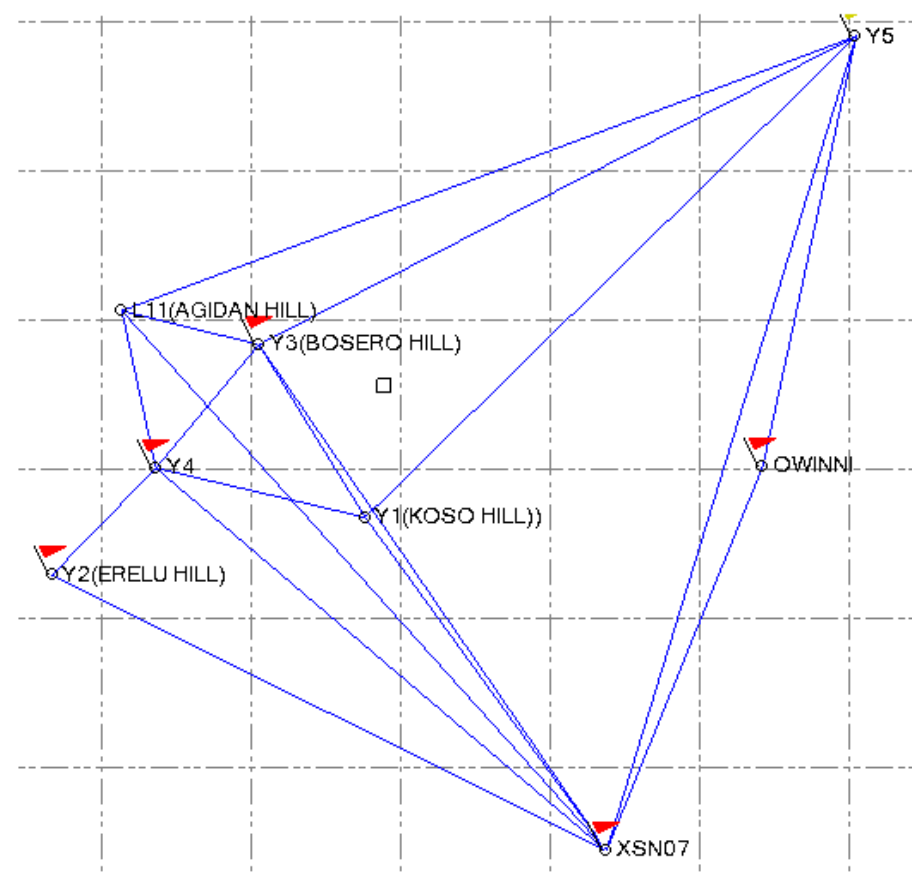

Figure 5 : Processed Network Baseline diagram (Not drawn to scale)

same condition should exist for the $Y$ and $Z$ components. These loop misclosure conditions are very similar to the leveling loop misclosures imposed in differential leveling and latitude and departure misclosures imposed in closed-polygon traverses. An unusually large misclosure within any loop will indicate that either a blunder or a large random error exists in one (or more) of the baselines of the loop. To compute loop misclosures, denoted as $c X, c y$ and $c Z$, the baseline components are simply added algebraically for the loop chosen. The closures in $X, Y$ \& $Z$ for the individual sessions are;

$$
\begin{aligned}
& \mathrm{CX}_{1}=\Delta \mathrm{X}_{\mathrm{AB}}+\Delta X_{\mathrm{BG}}+\Delta X_{\mathrm{GA}} \ldots \ldots \ldots \ldots \ldots \ldots \ldots \ldots \\
& \mathrm{Cy}_{1}=\Delta \mathrm{y}_{\mathrm{AB}}+\Delta y_{\mathrm{BG}}+\Delta y_{\mathrm{GA}} \ldots \ldots \ldots \ldots \ldots \ldots \ldots \ldots \ldots \\
& \mathrm{CZ}_{1}=\Delta \mathrm{Z}_{\mathrm{AB}}+\Delta Z_{\mathrm{BG}}+\Delta Z_{\mathrm{GA}} \ldots \ldots \ldots \ldots \ldots \ldots \ldots \ldots \\
& \mathrm{CX}_{2}=\Delta \mathrm{X}_{\mathrm{AD}}+\Delta X_{\mathrm{DF}}+\Delta X_{\mathrm{FA}} \ldots \ldots \ldots \ldots \ldots \ldots \ldots \ldots \ldots \ldots \\
& \mathrm{Cy}_{2}=\Delta \mathrm{y}_{\mathrm{AD}}+\Delta y_{\mathrm{DF}}+\Delta y_{\mathrm{FA}} \ldots \ldots \ldots \ldots \ldots \ldots \ldots \ldots \\
& \mathrm{CZ}_{2}=\Delta \mathrm{ZAD}+\Delta Z_{\mathrm{DF}}+\Delta \mathrm{Z}_{\mathrm{FA}} \ldots \ldots \ldots \ldots \ldots \ldots \ldots \ldots \\
& \mathrm{CX}_{3}=\Delta \mathrm{X}_{\mathrm{AE}}+\Delta X_{\mathrm{EF}}+\Delta X_{\mathrm{FA}} \ldots \ldots \ldots \ldots \ldots \ldots 20 \\
& \mathrm{Cy}_{3}=\Delta \mathrm{y}_{\mathrm{AE}}+\Delta y_{\mathrm{EF}}+\Delta y_{\mathrm{FA}} \ldots \ldots \ldots \ldots \ldots \ldots \ldots \ldots \ldots \ldots \ldots \\
& \mathrm{CZ}_{3}=\Delta \mathrm{ZAE}_{\mathrm{AE}}+\Delta Z_{\mathrm{EF}}+\Delta Z_{\mathrm{FA}} \ldots \ldots \ldots \ldots \ldots \ldots \ldots .22
\end{aligned}
$$

Solutions from the equations above are used in computing for the resultant closure for the loops in each session. The resultant closure is given by the equation shown below.

$$
\text { Resultant closure }(c e)=\sqrt{\left(c x^{2}+c y^{2}+c z^{2}\right)}
$$


For evaluation purposes, loop misclosures are expressed in terms of the rations of resultant misclosures to the total loop lengths. They are given in part per million (ppm).

$$
\begin{aligned}
& c e=\sqrt{\left(c x^{2}+c y^{2}+c z^{2}\right)} \\
& \text { ppm }=\frac{c e}{\text { Loop length }} \times 1,000,000
\end{aligned}
$$

Where $c e$ is the Loop closure error [9].

The results of the closures and ppm values, as shown by table 7 below, indicate a high level of consistency in the observations. It further indicates that there were neither possible blunders nor random errors in any of the measured loops.

Table 7: Loop Closure Analysis of XSN07 - Y3 - Y4

\begin{tabular}{|l|r|r|r|r|l|l|}
\hline Baseline & DX & DY & DZ & Distance & $\begin{array}{l}\text { Resultant } \\
\text { Misclosure }\end{array}$ & $\begin{array}{l}\text { ppm } \\
\text { ratio }\end{array}$ \\
\hline $\begin{array}{l}\text { XSN07 - } \\
\text { Y3 }\end{array}$ & -617.26 & -4693.13 & 6730.45 & 8228.316047 & & \\
\hline Y3 - Y4 & 282.513 & -1366.04 & -1640.64 & 2153.50377 & & \\
\hline $\begin{array}{l}\text { Y4 - } \\
\text { XSN07 }\end{array}$ & 334.717 & 6059.16 & -5089.821 & 7920.336684 & & \\
\hline & -0.03 & -0.01 & -0.011 & 18302.1565 & 0.033481338 & 1.829366 \\
\hline
\end{tabular}

Table 8: Loop Closure Analysis of XSN07 - Y5 - Y3

\begin{tabular}{|l|r|r|r|r|r|l|}
\hline Baseline & DX & DY & DZ & Distance & $\begin{array}{c}\text { Resultant } \\
\text { Misclosure }\end{array}$ & $\begin{array}{c}\text { ppm } \\
\text { ratio }\end{array}$ \\
\hline $\begin{array}{l}\text { XSN07 } \\
- \text { Y5 }\end{array}$ & -1661.05 & 3258.91 & 10815.9 & 11417.67391 & & \\
\hline $\begin{array}{l}\text { Y3 - } \\
\text { XSN07 }\end{array}$ & 617.26 & 4693.13 & -6730.45 & 8228.33132 & & \\
\hline Y5 - Y3 & 1043.806 & -7952.03 & -4085.46 & 9000.84971 & & \\
\hline & 0.015 & 0.01 & -0.01 & 28646.85494 & 0.020615528 & 0.719644 \\
\hline
\end{tabular}

As noted earlier, because GPS networks contain redundant observations, they must be adjusted to make all coordinate differences consistent.

\section{Least Squares Adjustment}

\section{Observation Equations}

In applying least squares to the problem of adjusting baselines in GPS networks, observation equations are written that relate station coordinates to the coordinate differences observed and their residual errors. Observation equations for each measured baseline component are given below: Note that Point $\mathrm{A}$ is the fixed point and is used only for check but not used in the adjustment. 


$$
\begin{aligned}
& \partial \mathrm{XB}=\left[\mathrm{X}_{\mathrm{A}}+\Delta X_{\mathrm{AB}}-X_{\mathrm{B}}\right] \\
& \partial \mathrm{YB}=\left[\mathrm{Y}_{\mathrm{A}}+\Delta Y_{\mathrm{AB}}-Y_{\mathrm{B}}\right] \text {. . . . . . (27) } \\
& \partial_{\mathrm{ZB}}=\left[\mathrm{Z}_{\mathrm{A}}+\Delta Z_{\mathrm{AB}}-Z_{\mathrm{B}}\right] \\
& \partial \mathrm{xC}=\left[\mathrm{X}_{\mathrm{A}}+\Delta X_{\mathrm{AC}}-X_{\mathrm{C}}\right] \\
& \partial \mathrm{YC}=\left[\mathrm{Y}_{\mathrm{A}}+\Delta Y_{\mathrm{AC}}-Y_{\mathrm{C}}\right] \quad . \quad \text {. } \quad . \quad \text { (30) } \\
& \partial \mathrm{zC}=\left[\mathrm{Z}_{\mathrm{A}}+\Delta Z_{\mathrm{AC}}-Z_{\mathrm{C}}\right] \\
& \partial \mathrm{XD}=\left[\mathrm{X}_{\mathrm{A}}+\Delta X_{\mathrm{AD}}-X_{\mathrm{D}}\right] \\
& \partial \mathrm{YD}=\left[\mathrm{Y}_{\mathrm{A}}+\Delta Y_{\mathrm{AD}}-Y_{\mathrm{D}}\right] \\
& \partial \mathrm{ZD}=\left[\mathrm{Z}_{\mathrm{A}}+\Delta Z_{\mathrm{AD}}-Z_{\mathrm{D}}\right] \\
& \partial \mathrm{XE}=\left[\mathrm{X}_{\mathrm{A}}+\Delta X_{\mathrm{AE}}-X_{\mathrm{E}}\right] \\
& \partial \mathrm{YE}=\left[\mathrm{Y}_{\mathrm{A}}+\Delta Y_{\mathrm{AE}}-Y_{\mathrm{E}}\right] \quad . \quad \text {. } \quad . \quad \text {. } \\
& \partial \mathrm{ZE}=\left[\mathrm{Z}_{\mathrm{A}}+\Delta Z_{\mathrm{AE}}-Z_{\mathrm{E}}\right] \\
& \partial \mathrm{XF}=\left[\mathrm{X}_{\mathrm{A}}+\Delta X_{\mathrm{AF}}-X_{\mathrm{F}}\right] \\
& \partial \mathrm{YF}=\left[\mathrm{Y}_{\mathrm{A}}+\Delta Y_{\mathrm{AF}}-Y_{\mathrm{F}}\right] \quad \text {. . . . . (39) } \\
& \partial_{\mathrm{ZF}}=\left[\mathrm{Z}_{\mathrm{A}}+\Delta Z_{\mathrm{AF}}-Z_{\mathrm{F}}\right] \\
& \partial \mathrm{XG}=\left[\mathrm{X}_{\mathrm{A}}+\Delta X_{\mathrm{AG}}-X_{\mathrm{G}}\right] \cdot . \quad \cdot \quad \cdot \quad \cdot \quad-(41) \\
& \partial \mathrm{YG}=\left[\mathrm{Y}_{\mathrm{A}}+\Delta Y_{\mathrm{AG}}-Y_{\mathrm{G}}\right] \text {. . . . . . (42) } \\
& \partial \mathrm{ZG}=\left[\mathrm{Z}_{\mathrm{A}}+\Delta Z_{\mathrm{AG}}-Z_{\mathrm{G}}\right] \\
& \partial \mathrm{XG}_{-} \partial \mathrm{X \textrm {B }}=\left[\mathrm{X}_{\mathrm{B}}+\Delta X_{\mathrm{BG}}-X_{\mathrm{G}}\right] \\
& \partial_{\mathrm{YG}} \partial \mathrm{XB}=\left[Y_{\mathrm{B}}+\Delta Y_{\mathrm{BG}}-Y_{\mathrm{G}}\right] \quad \text {. . . . . (45) } \\
& \partial \mathrm{ZG}_{-} \partial \mathrm{X \textrm {B }}=\left[\mathrm{Z}_{\mathrm{B}}+\Delta Z_{\mathrm{BG}}-Z_{\mathrm{G}}\right] \quad \text {. } \quad \text {. } \quad \text {. }(46) \\
& \partial \mathrm{XD}_{-} \partial \mathrm{XF}=\left[\mathrm{X}_{\mathrm{F}}+\Delta X_{\mathrm{FD}}-X_{\mathrm{D}}\right] \quad \text {. } \quad . \quad \text {. } \quad \text { (47) } \\
& \partial \mathrm{YD}_{-} \partial \mathrm{XF}=\left[\mathrm{Y}_{\mathrm{F}}+\Delta Y_{\mathrm{FD}}-Y_{\mathrm{D}}\right] \quad \text {. . . . . . }(48) \\
& \partial \mathrm{ZD} \_\partial \mathrm{XF}=\left[\mathrm{ZF}_{\mathrm{F}}+\Delta Z_{\mathrm{FD}}-Z_{\mathrm{D}}\right] \quad . \quad . \quad . \quad . \quad \text {. }(49) \\
& \partial \mathrm{XE}_{-} \partial \mathrm{XF}=\left[\mathrm{X}_{\mathrm{F}}+\Delta X_{\mathrm{FE}}-X_{\mathrm{E}}\right] \quad . \quad \quad . \quad \quad \quad \quad . \quad(50) \\
& \partial \mathrm{YE}_{2} \partial \mathrm{XF}=\left[\mathrm{Y}_{\mathrm{F}}+\Delta Y_{\mathrm{FE}}-Y_{\mathrm{E}}\right] \quad \text {. } \quad . \quad \text {. } \quad \text { (51) } \\
& \partial_{\mathrm{ZE}} \_\partial \mathrm{XF}=\left[\mathrm{ZF}_{\mathrm{F}}+\Delta Z_{\mathrm{FE}}-Z_{\mathrm{E}}\right] \quad \text {. } \quad . \quad \text {. } \quad \text { (52) }
\end{aligned}
$$

Observation equations of the foregoing form were written for all measured baselines in any figure. For figure (3), a total of 17 baselines were observed, so the number of observation equations that can be developed is 51 . Also, stations Y1, Y2, Y3, Y4, Y5, OWINNI and L11 each have three unknown coordinates, for a total of 21 
unknowns in the problem. Thus, there are $51-21=30$ redundant observations in the network. The 51 observation equations can be expressed in the form $\mathrm{AX}=\mathrm{L}+\mathrm{V}$

Where $A$ is the coefficient matrix ( $\mathrm{A}$ is in $\mathrm{X} \mathrm{n}$ with $\mathrm{m}>\mathrm{n}$ )

$\mathrm{L}$ is the matrix of absolute terms

$\mathrm{V}$ is the residuals (errors)

$\mathrm{X}$ is the matrix of unknown parameters (least-square solution)

\section{Normal Equation (N)}

Normal equation is written as $\mathrm{AX}=\mathrm{L}+\mathrm{V}$

The above equation can be normalized by pre multiplying by $\left(\mathrm{A}^{\mathrm{T}} \mathrm{W}\right)$ to obtain

$$
\left(\mathrm{A}^{\mathrm{T}} \mathrm{WA}\right) \mathrm{x}=\left(\mathrm{A}^{\mathrm{T}} \mathrm{WL}\right)+\left(\mathrm{A}^{\mathrm{T}} \mathrm{WV}\right), \quad \text { but }\left(\mathrm{A}^{\mathrm{T}} \mathrm{WV}\right)=0 \text {, so }
$$

This reduces to the form $\mathrm{NX}=\mathrm{B}-\cdots-$ - Normal equation

$$
\mathrm{X}=\left(\mathrm{A}^{\mathrm{T}} \mathrm{WA}\right)^{-1}\left(\mathrm{~A}^{\mathrm{T}} \mathrm{WL}\right)-\cdots \quad \mathrm{X}=\mathrm{N}^{-1} \mathrm{~B}
$$

Reference Standard deviation $\left(\delta_{0}\right)=\sqrt{\frac{V^{T} W V}{M-N}}$

Where $\mathrm{M}=$ number of equations \& $\mathrm{N}=$ number of unknowns.

The covariance matrix $(\Sigma)=\delta^{2} 0\left(\mathrm{~A}^{\mathrm{T}} \mathrm{WA}\right)^{-1}---\delta^{2} \mathrm{~N}^{-1}$

Figure Standard deviation of adjusted quantities $(\sigma)=\delta 0 \sqrt{\Sigma}$

Standard Errors $(\sigma \dot{\mathrm{x}})=\sqrt{\operatorname{diag}(\Sigma)}$

\section{The Covariance and Weight Matrices}

Note that the observation equations for GPS network adjustment are linear and that the only nonzero elements of the A matrix are either 1 or -1 . In GPS relative positioning, the three observed baseline components are correlated. Therefore, a $3 \times 3$ covariance matrix is derived for each baseline as a product of the least squares adjustment of the carrier-phase measurements $[9,10]$. This covariance matrix is used to properly weight the observations in the network adjustment. The weight matrix for any PGS networks is therefore a block-diagonal type, with an individual $3 \times 3$ matrix for each baseline observed on the diagonal to provide the correlation that exists between baselines observed simultaneously.

The Covariance $(\Sigma)$ and Weight (W) Matrices for baselines of the network in figure (4.3) are therefore of the form:

$$
\Sigma_{\mathrm{AB}}=\left[\begin{array}{ccc}
\sigma_{X}^{2} & \sigma x y & \sigma x z \\
\sigma x y & \sigma_{y}^{2} & \sigma y z \\
\sigma x z & \sigma y z & \sigma_{z}^{2}
\end{array}\right] \quad \text { and } \quad \mathrm{W}=\sum_{\mathrm{AB}}-1
$$

The complete covariance and weight matrices for the network of figure (5) both have dimensions of $51 \times 51$. The system of observation equation (9) is solved by least squares. This yields the most probable values for the coordinates of the unknown stations. The complete output for figure 4.2 obtained using the program ADJUST follows. 
Table 9: Adjusted Baseline Vectors

\begin{tabular}{|l|l|r|r|r|r|r|r|}
\hline From & To & \multicolumn{1}{l}{ dX } & \multicolumn{1}{l|}{ d } & \multicolumn{1}{l|}{ dZ } & \multicolumn{1}{l|}{ V } & \multicolumn{1}{l|}{ V } & \multicolumn{1}{l|}{$\mathbf{z}$} \\
\hline XSN07 & OWINNI & -817.432 & 2054.851 & 5111.214 & -0.0027 & -0.0023 & -0.0016 \\
\hline XSN07 & Y5 & -1661 & 3258.909 & 10815.92 & 0.052 & 0.0003 & 0.0065 \\
\hline XSN07 & Y1 & -380.581 & -3255.35 & 4436.219 & -0.0685 & -0.0089 & -0.0038 \\
\hline XSN07 & Y3 & -617.263 & -4693.13 & 6730.451 & -0.003 & -0.0002 & 0.0014 \\
\hline XSN07 & Y4 & -334.735 & -6059.16 & 5089.82 & -0.0182 & -0.0031 & -0.0008 \\
\hline XSN07 & Y2 & -19.892 & -7436.59 & 3675.532 & -0.0124 & 0.0065 & -0.0109 \\
\hline XSN07 & L11 & -505.662 & -6525.28 & 7190.868 & 0.1563 & 0.0018 & 0.0383 \\
\hline Y5 & OWINNI & 843.567 & -1204.06 & -5704.71 & 0.0133 & 0.0294 & -0.0001 \\
\hline Y5 & Y3 & 1043.736 & -7952.04 & -4085.47 & -0.07 & -0.0045 & -0.0071 \\
\hline Y4 & Y3 & -282.528 & 1366.031 & 1640.631 & -0.0148 & -0.0051 & -0.0068 \\
\hline Y4 & Y2 & 314.843 & -1377.43 & -1414.29 & -0.0022 & -0.0035 & 0.0049 \\
\hline Y5 & Y1 & 1280.419 & -6514.25 & -6379.7 & 0.1395 & 0.0099 & 0.0157 \\
\hline Y5 & L11 & 1155.337 & -9784.19 & -3625.05 & 0.0333 & 0.0025 & 0.0028 \\
\hline Y4 & L11 & -170.927 & -466.123 & 2101.048 & 0.0025 & 0.0029 & -0.003 \\
\hline Y3 & L11 & 111.601 & -1832.15 & 460.417 & -0.0007 & -0.0019 & 0.0018 \\
\hline Y4 & Y1 & -45.845 & 2803.815 & -653.601 & -0.0123 & 0.0022 & -0.002 \\
\hline Y3 & Y1 & 236.682 & 1437.784 & -2294.23 & -0.0265 & 0.0014 & -0.0012 \\
\hline
\end{tabular}

Degrees of Freedom $=30$

Reference Variance $=0.622$

Standard Deviation of Unit Weight $= \pm 0.789$

It can be seen that differences between the unadjusted Distance vector and adjusted distance vector exists only in the decimal part of the coordinates. This further confirms the pre-adjustment test (loop closure) results, indicating a higher level of consistency of the measurements. These differences, no matter how small, point to the fact that rigorous least square adjustment is necessary for any serious geodetic work.

Table 10: Advance Statistical Values

\begin{tabular}{|l|l|r|r|r|r|}
\hline \multicolumn{1}{|c|}{ From } & \multicolumn{1}{|c|}{ To } & \multicolumn{1}{c|}{${ }_{\text {S }}$} & \multicolumn{1}{c|}{ Slope } & $\begin{array}{c}\text { Dist } \\
\text { Prec }\end{array}$ & \multicolumn{1}{c|}{ ppm } \\
\hline XSN07 & OWINNI & 0.0502 & $5,569.12$ & 111,000 & 9.01 \\
\hline XSN07 & Y5 & 0.0314 & $11,417.69$ & 363,000 & 2.75 \\
\hline XSN07 & Y1 & 0.029 & $5,515.63$ & 190,000 & 5.26 \\
\hline XSN07 & Y3 & 0.023 & $8,228.33$ & 358,000 & 2.79 \\
\hline XSN07 & Y4 & 0.0265 & $7,920.34$ & 299,000 & 3.34 \\
\hline XSN07 & Y2 & 0.0293 & $8,295.35$ & 283,000 & 3.53 \\
\hline XSN07 & L11 & 0.0235 & $9,723.35$ & 414,000 & 2.42 \\
\hline Y5 & OWINNI & 0.0539 & $5,891.10$ & 109,000 & 9.17 \\
\hline
\end{tabular}




\begin{tabular}{|l|l|r|r|r|r|} 
Y5 & Y3 & 0.0268 & $9,000.85$ & 336,000 & 2.98 \\
\hline Y4 & Y3 & 0.021 & $2,153.49$ & 102,000 & 9.8 \\
\hline Y4 & Y2 & 0.0156 & $1,999.16$ & 129,000 & 7.75 \\
\hline Y5 & Y1 & 0.0305 & $9,207.36$ & 302,000 & 3.31 \\
\hline Y5 & L11 & 0.0274 & $10,497.92$ & 383,000 & 2.61 \\
\hline Y4 & L11 & 0.0209 & $2,158.91$ & 103,000 & 9.71 \\
\hline Y3 & L11 & 0.0088 & $1,892.41$ & 215,000 & 4.65 \\
\hline Y4 & Y1 & 0.0243 & $2,879.35$ & 118,000 & 8.47 \\
\hline Y3 & Y1 & 0.0224 & $2,717.86$ & 121,000 & 8.26 \\
\hline
\end{tabular}

Table 11: Adjusted Geocentric Coordinates of the Geodetic Points

\begin{tabular}{|l|c|c|c|c|c|c|}
\hline \multicolumn{1}{|c|}{ Station } & $\mathbf{X}$ & $\mathrm{Y}$ & $\mathbf{Z}$ & Sx & Sy & Sz \\
\hline XSN07 & $6,304,212.69$ & $435,327.36$ & $864,448.86$ & & & \\
\hline OWINNI & $6,303,395.26$ & $437,382.21$ & $869,560.07$ & 0.0103 & 0.0111 & 0.0111 \\
\hline Y5 & $6,302,551.69$ & $438,586.27$ & $875,264.78$ & 0.0048 & 0.0061 & 0.0061 \\
\hline Y1 & $6,303,832.11$ & $432,072.02$ & $868,885.08$ & 0.0277 & 0.0050 & 0.0070 \\
\hline Y3 & $6,303,595.43$ & $430,634.23$ & $871,179.31$ & 0.0220 & 0.0042 & 0.0051 \\
\hline Y4 & $6,303,877.95$ & $429,268.20$ & $869,538.68$ & 0.0256 & 0.0042 & 0.0055 \\
\hline Y2 & $6,304,192.80$ & $427,890.78$ & $868,124.39$ & 0.0282 & 0.0051 & 0.0060 \\
\hline L11 & $6,303,707.03$ & $428,802.08$ & $871,639.73$ & 0.0225 & 0.0040 & 0.0053 \\
\hline
\end{tabular}

\section{Data Analysis}

\section{Error Ellipse}

The error ellipses and their respective orientations of the adjusted stations were respectively computed using equations (58a and 58b) and (59) to present graphically the directional stations positions accuracy. The computed semimajor and semiminor axes were scaled with $95 \%$ confidence expansion factor (2.44788) using equation $(60 \mathrm{a}$ and $60 \mathrm{~b})$.

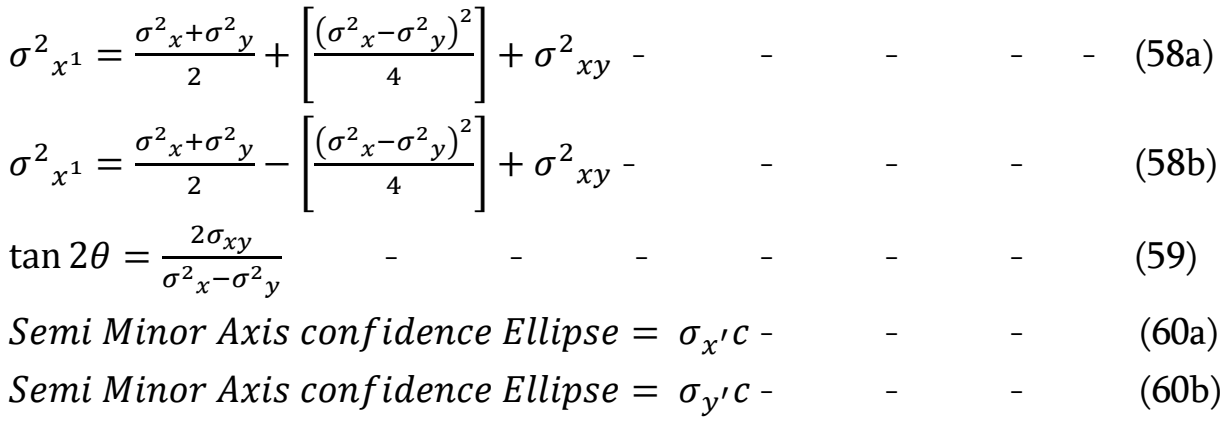

Table 12: Semimajor Axes, Semiminor Axes and Orientations of the Adjusted Stations

\begin{tabular}{|c|c|c|c|c|c|c|}
\hline \multicolumn{7}{|c|}{ 95\% Confidence Error Ellipses } \\
\hline \multirow{3}{*}{ Station } & $\begin{array}{c}\text { Standard Error } \\
\text { in Northing }\end{array}$ & $\begin{array}{c}\text { Standard } \\
\text { Error in } \\
\text { Easting }\end{array}$ & $\begin{array}{c}\text { 2D Chi Sqr } \\
\text { Mult 95.0 }\end{array}$ & $\begin{array}{c}\text { Semi- } \\
\text { Major }\end{array}$ & $\begin{array}{c}\text { Semi- } \\
\text { Minor }\end{array}$ & $\begin{array}{c}\text { Azimuth } \\
\text { D M S }\end{array}$ \\
\hline
\end{tabular}




\begin{tabular}{|c|c|c|c|c|c|c|}
\hline XSN07 & 0 & 0 & 0 & 0 & 0 & 0 \\
\hline OWINNI & 0.0479 & 0.0103 & 2.44788 & 0.11725 & 0.02521 & 323100 \\
\hline Y1 & 0.0304 & 0.0048 & 2.44788 & 0.07442 & 0.01175 & 443612 \\
\hline Y5 & 0.0277 & 0.0050 & 2.44788 & 0.06781 & 0.01224 & 424558 \\
\hline Y3 & 0.0220 & 0.0042 & 2.44788 & 0.05385 & 0.01028 & 422504 \\
\hline Y4 & 0.0256 & 0.0042 & 2.44788 & 0.06267 & 0.01028 & 423521 \\
\hline Y2 & 0.0282 & 0.0051 & 2.44788 & 0.06903 & 0.01248 & 350652 \\
\hline L11 & 0.0225 & 0.0040 & 2.44788 & 0.05508 & 0.00979 & 431519 \\
\hline
\end{tabular}

Table 12 presents the computed semimajor axes, semiminor axes and orientations of the adjusted positions. Also, figure 6 shows the plot of the adjusted stations positions error ellipses. These were done to present graphically the adjusted stations positions directional accuracy. It can be seen from table 12 that the computed/scaled semimajor and semiminor axes of the adjusted stations positions were all within centimetre standard, which implies the high accuracy of the adjusted stations coordinates. It can also be seen from table 12 and figure 6 that the orientations of the computed error ellipses were between $0^{\circ}$ and $90^{\circ}$, which implies that accuracy of the adjusted stations coordinates were to the north-east direction. Also the spheres are all almost of equal size. This also shows the reliability of the network.

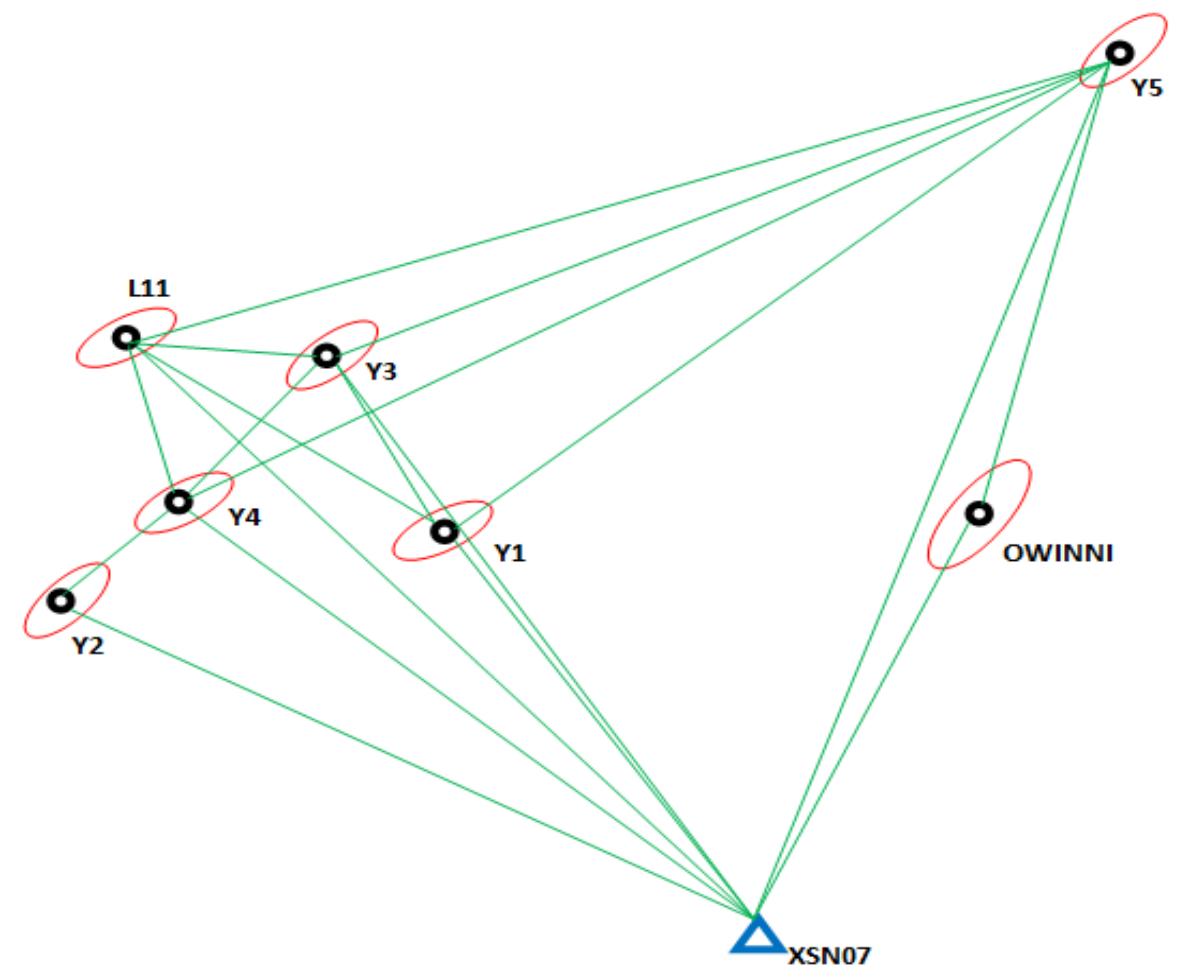

Figure 6: Plot of Error Ellipses of the Adjusted Stations

The Mode of Maintenance and Possible Suggestions
Maintenance of geodetic network is, therefore an inevitable necessity so that it is updated on a periodic basis so to maintain high accuracy as well as 
matching with the successive realizations of the ITRF. There exist two different approaches of frame maintenance which are the dynamic and the semi dynamic approaches. In the former, positions are assumed to be dynamic and are valid only for a specific epoch whereas in the latter, positions are valid within the entire period between successive releases of the global reference frame ITRF.

Geodetic reference frames are subject to regular maintenance due to addition of new points, tectonic motions, crustal deformations, volcanic uplifts, postglacial rebound, correction of survey errors and blunders. Usually, the maintenance and updating of modern frames uses a semi-dynamic approach, which periodically updates the coordinates with the new release of the ITRF versions.

This approach uses scientific software such as Bernese v5.0, GAMIT and GPSY OASIS II. With reference to $[11,12,13]$, and as cited in [14] the mathematical maintenance of the modern geodetic reference frames at any required epoch $t$ uses the generalized Helmet transformation model to account for the rotation factor of the plate motion.

\section{IV.CONCLUSION}

In conclusion a first order geodetic reference network of seven primary controls has been reestablished in parts of Oyo state using DGPS. This work will be used by every prospective user all over Nigeria. The following are contributions to knowledge: One

1. The geodetic network that was established using traditional method is now re-established using DGPS (modern techniques) which produce a more reliable network in parts of Oyo state.

2. Secondly, this research work now provides the new network in WGS84.
The establishment of this network will encourage the use of GNSS technology in general, and GPS in particular, by Oyo surveyors and students in the execution of their daily surveying duties. This will enhance accuracy and reduce numerous land conflicts resulting from poorly demarcated boundaries established by means of compass.

During the course of the field work some limitations were encountered, such as; one, religious groups have pitched their tents and alters on some of the hills, example Owinni hill, Koso hill and Erelu hill and so it was difficult setting up the instruments it took about three hours begging the priest to allow us set-up the instrument. This makes the work to take more time and days. Two, another serious problem was locating the existing control point on Ikoloba hill using the existing coordinates with the help of handheld GPS, it took extra effort to locate the point because the handheld GPS used for navigation was showing meters away from the point.

Also, the geodetic network has been re-observed, re-established and updated using model techniques (GNSS). The most probable values were determined using Least Square Adjustment. The new network provides coordinates in the WGS84 system to be which can be transformed to any local system when transformation parameters are available. It will reduce, if not eliminate, the use of compass survey and the metes and bounds method for property location and demarcation as the new network provides reference stations established with sub-centimetre accuracy.

\section{ACKNOWLEDGEMENT}

The team of researchers wish to acknowledge Federal School of Survey, Oyo, Oyo state of Nigeria for allowing access to relevant record, valuable data and usage of survey equipment for the experimental campaign.

\section{REFERENCES}

[1]. I. A. Fotiou, "Parametric Optimization and Optimal Control Using Algebraic Geometry 
Methods" Int. J Control. 2006, 79(11) pp13401358.

[2]. G. Retscher, "Accuracy Performance of Virtual Reference Station (VRS) Networks"Positioning 2002, 1(03) pp 94.

[3]. M. M. Lonchay, “ Precision of SatelliteP positioning and the Impact of Satellite Geomtric. University of Leige, Faculty of Science Department of Geograpghy, Geomatics Unit (ODISSEA) 2009.

[4]. B. M. Ameh, "Determination of Components of Deflection of the Vertical of Lobi Area of Makurdi, Benue State, Using GPS (GNSS) and Precise Levelling Observations," Unpublished M.S.C. Thesis of the Department of Surveying and Geo-informatics, Nnamdi Azikiwe University Awka (2013).

[5]. C. S. Bundoo, "Establishing a Geodetic Reference Network in Montserrado County Liberia, Using GNSS Technology". Unpublished M.Sc thesis, Kwame Nkurmah University of Science and Technology (KNUST), Kumasi, Ghana. Master Abstract International, 2013.

[6]. www.researchgate.net, 2018

[7]. FGCC, "Geospatial Positioning Accuracy Standards”. Federal Geodetic Control, FGDCSTD-007.1-1998, Federal Geographic Data Committee Secretariat, 1998.

[8]. USACE, "Engineering and Design: Survey Markers and Monumentation". US Army Corps of Engineers, EM1110-1-1002. 01103/2012. Accessed on 23April 2018 from www.publications. Usacearmy.mil/portals/76/ manual no 1110-1-1002, 2012.

[9]. C. D. Ghilani and P. R. Wolf, "Elementary Surveying. An Introduction to Geomatics", Twelfth Edition Pearson Prentice Hall Pearson Education International, U.S.A. 2008 pp 278442.
[10]. P. A. Cross, "Advanced Least Squares Aapplied to Position Ffixing". University of East, 1994

[11]. M. Craymer, R. Ferland, R. Snay. "Realization and Unification of NAD83 in Canada and the US via the ITRF", 2006, DOI: 10.1007/978-3642-59745-9_20.

[12]. R. Dach, U. Hugentobler, P. Fridez \& M. Meindl, "Bernese GPS Software" Version 5.0. Bern: Astronomical Institute, University of Bern, 2007.

[13]. R. F. Leandro, M. C. Santos, and R. B. Langley () "GAPS: the GPS Analysis and Positioning Software - A Brief Overview." Proceedings of the ION GNSS, 20th International Technical Meeting of the Satellite Division, Fort Worth, Texas, September 25-28, pp. 18007-1811, 2007.

[14]. D. M. James, "Establishment of A New Geospatial Frame for Tanzania-TZRF1O". Unpublished M.Sc thesis, University of New Brunswick Canada. Master Abstract International, 2009.

\section{Cite this article as :}

Ikharo I. Blessing, Matthew N. Ono, Olaniyi Saheed S., " Re-Establishment and Maintenance of Geodetic Networks in Parts of Oyo State Using Modern Techniques", International Journal of Scientific Research in Science and Technology(IJSRST), Print ISSN : 2395-6011, Online ISSN : 2395-602X, Volume 6, Issue 4, pp.167-183, July-August-2019. Available at doi : $\quad$ https://doi.org/10.32628/IJSRST196435 Journal URL : http://ijsrst.com/IJSRST196435 